\title{
Exploring Idea Convergence and Conceptual Combination in Open Innovative Crowdsourcing from a Cognitive Load Perspective
}

\author{
Shixuan $\mathrm{Fu}$ \\ University of \\ International Business \\ and Economics, \\ fsx8888@163.com
}

\author{
Xusen Cheng \\ University of \\ International Business \\ and Economics, \\ xusen.cheng@uibe.edu.cn
}

\author{
Triparna de Vreede \\ University of South \\ Florida, \\ tdevreede@usf.edu
}

\author{
Gert-Jan de Vreede \\ University of South \\ Florida, \\ gdevreede@usf.edu
}

\author{
Isabella Seeber \\ University of Innsbruck, \\ isabella.seeber@uibk.ac.at
}

\author{
Ronald Maier \\ University of Innsbruck, \\ ronald.maier@uibk.ac.at
}

\author{
Barbara Weber \\ Technical University of Denmark, \\ bweb@dtu.dk
}

\begin{abstract}
Open innovative crowdsourcing has received increasing attention. This study sets out to investigate idea convergence and generation in open innovative crowdsourcing communities from a cognitive load perspective to explore aspects of cognitive idea processing. We have conducted a laboratory experiment to investigate the effects of three manipulations (task complexity, idea presentation, and procedural guidance) on three types of cognitive load and the following idea convergence and generation quality. We have also examined the influencing mechanisms of cognitive loads on satisfaction with process and satisfaction with outcome. Our results show that the three cognitive loads have significant effects: Higher intrinsic cognitive load significantly leads to lower satisfaction with process and outcome. Higher extraneous cognitive load significantly leads to satisfaction with process. Higher germane cognitive load significantly leads to higher convergence quality and lower new idea generation quality.
\end{abstract}

\section{Introduction}

Many companies and organizations have integrated crowdsourcing into their research and development (R\&D) processes[1]. Online crowds work in the form of mass collaboration to answer the open calls for problems solving, creative designs, and collective new product development through crowdsourcing platforms [2]. Crowdsourcing, as an open innovation initiative, provides flexibility to users with diverse backgrounds to generate and select the most promising ideas [3]. In this research, we focus on idea generation and idea selection in the open innovation processes[4] as the success of these open innovation efforts depends on online crowds to generate and evaluate creative ideas [5].

Until now, most studies on crowdsourcing have been conceptual in nature [6] and have focused on the motivational factors related to user participation and engagement in the community [7]. Recently, there is increased attention for research on idea convergence in group problem solving contexts,i.e. the extraction of the most promising ideas from a large number of generated ideas $[3,8]$. Yet, work in this area is still at a nascent stage. Our understanding on how individuals cognitively process information during idea generation and convergence is still developing. Convergence is a critical part in an open innovation project as the organization or its delegate panel of judges typically does not have the time and cognitive resources to give a detailed assessment of each generated contribution.

Both idea convergence and idea generation are cognitive processes that involve retrieving information from working memory [9]. A person's working memory is a limited capacity cognitive system used to maintain and manipulate information. An individual's ability to process information and make decisions using their working memory is influenced by the cognitive load they experience. Cognitive load refers to the total amount of mental effort being used in the working memory [10]. Our study aims to gain a deeper understanding of individuals' cognitive processes during idea convergence and generation in an open innovative crowdsourcing context. Our goal is to design interventions that facilitate more effective idea convergence and generation processes and outcomes from cognitive load perspective.

Our study differs from existing studies that investigate idea generation or idea convergence separately [3][11][12]. We studied a holistic process involving both idea convergence and generation successively in this paper. First, we designed interventions for better idea convergence in the form of 
a laboratory experiment. We further investigated a subsequent phase of creative idea generation to study whether the interventions for idea convergence provide useful starting points for additional new idea development. Specifically, we aim to answer the following research question: What are the effects of interventions that aim to improve cognitive load on convergence quality, idea generation quality, satisfaction with process, and satisfaction with outcomes?

The remainder of this paper is organized as follows. The next section describes the related background for the study. Theory and hypothesis development will be addressed in section 3. The fourth section presents the research method, specifically in terms of the experiment design. We then present the results in section 5. Section 6 discusses the implications of our findings, limitations, and future research directions.

\section{Related background}

Crowdsourcing is defined as a social media technology enabled collaboration that involves dynamic online crowds to voluntarily contribute to open calls for participation [1][13]. Open innovation is a type of crowdsourcing where the organization seeks recommendations and ideas for innovative solutions beyond its organizational boundaries through an open call for contributions [14]. In short, open innovation refers to crowdsourcing for creative idea proposals and collective evaluations for innovations [15]. Open innovation makes use of the collective efforts and wisdom to generate massive numbers of user generated contents with diversified qualities [14].

While crowdsourcing has proven to be an effective tool to elicit a multitude of ideas in a short period of time, one of the challenges with this method is to identify the best ideas or the ideas that are worth pursuing [3][8]. The process of extracting a subset of the generated ideas that are worthy of further consideration is known as idea convergence, which is one of the five patterns of collaboration in teamwork [11][16]. Idea convergence requires individuals to deliberate and compare massive numbers of ideas and make the decisions to pick the promising ideas.

The success of open innovative crowdsourcing thus lies in the ability to identify high quality ideas from the pool of crowd generated ideas [8]. An appropriate convergence process is critical in that it provides preliminary filtration of ideas after the deliberation and comparison of all the generated contributions [17][18]. This can result in a fair amount of distillation especially if the goals of the convergence are clearly specified. Furthermore, the process of idea convergence can provide a new reference point for individuals for additional idea generation to enrich the extracted subset.

Idea generation is also one of the patterns of collaboration in teamwork [16]. It concerns a process where individuals working together produce new ideas, such as solutions to a problem or thoughts about a specific situation. Conceptual combination is a special form of idea generation that can occur after idea convergence. Conceptual combination involves the cognitive effort of combining two lower level concepts to create a higher-level concept that retains some elements of both lower level concepts and yet results in a new element that was not present in either. Conceptual combination has been widely used in creative endeavors to combine diverse concepts and words [19][20] and is gaining prominence in crowdsourcing research as well [21]. In crowdsourcing, the use of conceptual combination can result in further distillation of the existing ideas while enriching the value and creativity of the ones that were originally extracted from the initial idea set. One of the ways that this type of amalgamation of ideas can be attained is to pick one or more of the existing ideas that are unrelated to each other and blending them together in a meaningful manner while still meeting the convergence goals.

In this study, we aim to investigate two consecutive processes of idea processing in open innovative crowdsourcing, which respectively are idea convergence and idea generation through conceptual combination. Specifically, starting with an initial base set of ideas, we focus on idea convergence preceding idea generation through conceptual combination to investigate how the best ideas from a larger set can inspire additional ideas. To this end, we use cognitive load theory as our theoretical framework since both idea generation and convergence require individuals to have access to and process information. Information is dispersed in different mental elements that needs to be associated together to form new ideas [9][22]. Some of the common convergence methods are to ask participants to identify a subset of best ideas among all the ideas [11]. Viewing others' ideas facilitates the combinations of dispersed mental elements for new idea generation [21]. The next section introduces cognitive load theory and develops the exploratory hypotheses for our study.

\section{Theory and hypotheses development}

\subsection{Cognitive load theory}

Information processing theory posits that working memory (short-term memory) and long-term memory 
as two types of memory during cognitive information processing [21][23]. The limitation of working memory requires the optimization of working memory capacity to avoid or minimize cognitive overload [10]. Cognitive load theory (CLT) was developed on the assumption that humans have limited working memory. CLT argues that information processing can be facilitated through the interventions such as instructions, information presentation, and facilitating the formation and use of cognitive schema. We use CLT as a theoretical basis for our research on idea convergence and idea generation as both processes require cognitive effort. Especially when the amount of ideas and the difficulty of processing ideas exceed individuals' cognitive capabilities, they experience high cognitive load. Thus, it is assumed that a high level of cognitive effort and corresponding cognitive load will inhibit the idea convergence and generation process.

CLT distinguishes between three types of cognitive load: intrinsic cognitive load, extraneous cognitive load and germane cognitive load [10]. Intrinsic cognitive load refers to the degree of complexity inherent in the task. Apart from the inherent complexity of a task, individual differences (e.g. intellectual aptitude) also influence the perception of task difficulty. Extraneous cognitive load refers to the presentation and the organization of the materials to be processed. Extraneous cognitive load is increased by inadequate instructional material. It is mostly influenced by the manner in which the tasks and information are presented. The sum of intrinsic cognitive load and extraneous cognitive load is the total cognitive load an individual has to process in working memory. Germane cognitive load refers to the supportive design that is devoted to the processing, construction, and automation of schema. In long term memory, schema are repositories of information that are interlinked. Retrieving schema assists with the combination of information chunks and further eases the information processing load in working memory. Intrinsic cognitive load is encouraged to be managed, extraneous cognitive should be minimized, and germane cognitive load should be maximized [10].

Thus, following the logic of CLT, task performance will improve when cognitive load that is not relevant for schema construction, is reduced or removed. Based on the three types of cognitive load, Various researchers have used this logic to propose ways for decreasing mental load in the information processing, for example through strategies that promote schema development in long-term memory while easing the demands on working memory to improve learning complex tasks [24]. CLT is also a major theory for the investigation of cognitive processes and instructional design [25][26].

\subsection{Hypothesis development}

Task difficulty represents the manifestation of intrinsic cognitive load. Task complexity has been proposed and validated to have a negative influence on task performances [27]. One possible explanation is that complex tasks require higher level of working memory capacity to process the information [10]. An overabundant amount of information in complex tasks also leads to information overload, which is harmful for final task performance [27].

Extraneous cognitive load results from poor information presentation, which requires attention allocation to process the information [12]. Poor information presentation occupies part of the limited working memory capacity that individuals have available and thus negatively influences the ability to process information. Existing studies have focused on attention cues to ease extraneous cognitive load for better task performance [28].

Germane cognitive load relates to the construction and automation of schemas. Schemas provide instructional support for information processing [10]. Schemas such as automated deliberation guidance, process facilitation, and feedback mechanisms contribute to the inferring, differentiating, and organizing of information [10], and improve task performance [11][29]. For example, existing studies measured decision making quality [29], convergence quality [11], and idea generation quality [36] as proxies for their corresponding task performance.

Idea convergence is one of the most challenging team activities [30]. The challenge lies in the cognitive complexity of comparing and selecting the most promising ideas and the high number of ideas that typically need to be processed. To support convergence, team leaders such as facilitators often use structured procedures to provide schema for the team members [11]. The success of such interventions can be determined by assessing the quality of the idea convergence. Typically, idea convergence quality refers to the overall quality of ideas that have been shortlisted [11]. Thus, idea convergence quality can be considered as a measure for convergence task performance [31]. To explore the effect of the three types of cognitive load on convergence quality, we propose the following exploratory hypotheses:

Hypothesis 1a: Higher intrinsic cognitive load will produce lower idea convergence quality.

Hypothesis 1b: Higher extraneous cognitive load will produce lower idea convergence quality. 
Hypothesis 1c: Higher germane cognitive load will produce higher idea convergence quality.

Various intervention techniques have been developed to increase the numbers of generated ideas [32][33][34] and the creativity of the brainstormed ideas [9][35][36]. One class of techniques concerns categorization, which tends to cue attention of participants and facilitates the generation of ideas [32]. Categorization facilitates the organization of information that leads to lower extraneous cognitive load [10]. In addition, intrinsic cognitive load caused by task complexity sometimes leads to cognitive inertia such that participants are unwilling to make the effort to generate ideas [37]. Other types of interventions focus on stimuli to improve ideation quality. Stimuli serve as the catalyst to activate the associations of items stormed in working memory [9]. Stimulate can also be a source of instructional guidance to prompt germane cognitive load [10]. Based on the above, we propose the following exploratory hypotheses:

Hypothesis 2a: Higher intrinsic cognitive load will produce lower idea generation quality.

Hypothesis 2b: Higher extraneous cognitive load will produce lower idea generation quality.

Hypothesis 2c: Higher germane cognitive load will produce higher idea generation quality.

Satisfaction is an affective response related to the fulfilment of needs, expectation, or wishes [38]. Satisfaction with process and satisfaction with outcome are two dimensions of a satisfaction measurement that is typically used in team research [43]. If individuals feel dissatisfied towards the process guidance and task outcomes, they will be less likely to continue contributing their ongoing efforts [43]. Thus, satisfaction is an important predictor for sustained success of team processes and efforts.

Cognitive overload leads to frustration and dissatisfaction [10]. Interventions such as team facilitation techniques that optimize the capacity of working memory contribute to the avoidance of cognitive overload. For example, respondents report higher levels of satisfaction when they find the collaboration guidance adequate [38]. Adequate procedural guidance contributes to the formation of schema that could be stored in long term memory that ease the load of working memory. Further, existing studies have argued that task complexity has a negative correlation with satisfaction perceptions [31]. Results also show that improper information presentation leads to negative emotional arousal that triggers respondents' dissatisfaction perceptions [39]. Thus, we propose the following exploratory hypotheses:

Hypothesis 3a: Higher intrinsic cognitive load will produce lower satisfaction with process.
Hypothesis 3b: Higher extraneous cognitive load will produce lower satisfaction with process.

Hypothesis 3c: Higher germane cognitive load will produce higher satisfaction with process.

Hypothesis 4a: Higher intrinsic cognitive load will produce lower satisfaction with outcome.

Hypothesis 4b: Higher extraneous cognitive load will produce lower satisfaction with outcome.

Hypothesis 4c: Higher germane cognitive load will be associated with higher satisfaction with outcome.

The complete research model for this study is depicted in figure 1.

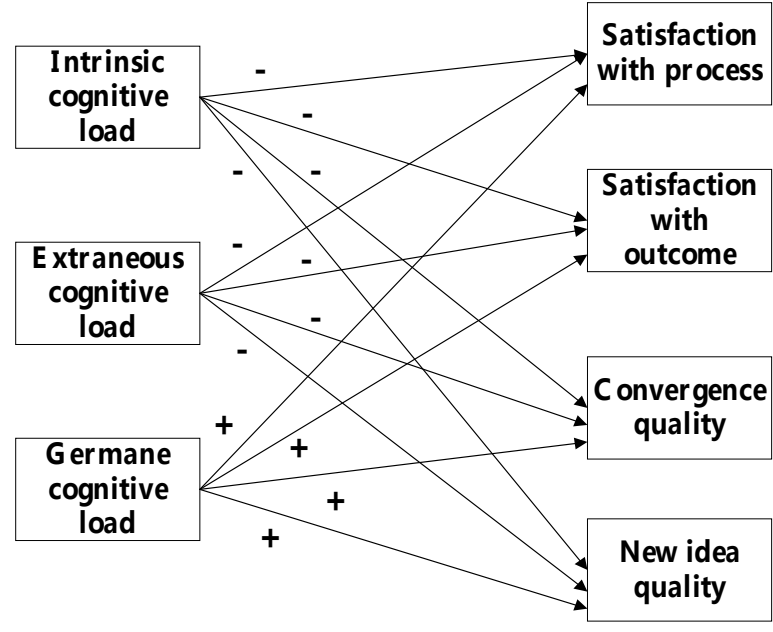

Figure 1. Research model

\section{Research method}

To test our hypotheses, we conducted a laboratory experiment. We used a $2 \times 2 \times 2$ factorial design to investigate the effects of task complexity (low vs. high intrinsic cognitive load), idea presentation (low vs. high extraneous cognitive load) and procedural guidance (not present vs. present germane cognitive load) on idea convergence quality and ideation creativity in open innovation crowdsourcing platforms. Specifically, we investigate whether cognitive load related interventions facilitate higher quality resulting from idea convergence and idea generation. We also determined whether the interventions were related to higher satisfaction with process and outcome.

\subsection{Task}

The task in this experiment was an open innovation task. It concerned the challenge, "How might we use technology to inspire all socioeconomic and multicultural groups to lead healthier lives". This challenge was proposed in an open innovation 
community, OpenIDEO, where it received broad participation. We randomly selected 100 user generated ideas from the community as the starting idea pool for the experiments. Participants were asked to work on these ideas in two activities: idea convergence and new idea generation (conceptual combination). First, participants were asked to extract the 10 most promising ideas from the starting idea pool.
Second, participants were asked to propose 5 creative ideas for technology support on healthy lives, based on the 10 ideas they picked in the first step. Each creative new idea had to be a combination of two of the selected top 10 ideas. Participants were given 45 and 15 minutes to finish activities 1 and 2 respectively. An overview of the experiment flow is shown in figure 2 .

$\left.\begin{array}{|c|c|c|}\hline \begin{array}{c}\text { Presentation of } \\ \text { starting idea pool } \\ \text { and experiment } \\ \text { instructions }\end{array} & \begin{array}{c}\text { Activity 1: } \\ \text { Idea Convergence }\end{array} & \begin{array}{c}\text { Activity 2: } \\ \text { Idea generation } \\ \text { (Conceptual } \\ \text { combination) }\end{array}\end{array}\right\} \begin{gathered}\text { Post-experiment } \\ \text { Survey }\end{gathered}$

Figure 2. Experiment tasks

\subsection{Subjects and procedures}

We have recruited 172 undergraduate students from a Chinese university to participate in the lab experiment.They were all volunteered to participate in this experiment. During the experiment, participants were randomly assigned into eight different experiment conditions (table 1).

Table 1. Experiment conditions

\begin{tabular}{|c|c|c|}
\hline $\begin{array}{c}\text { Treatment } \\
\text { variable }\end{array}$ & High groups & Low groups \\
\hline $\begin{array}{c}\text { Task } \\
\text { complexity }\end{array}$ & 100 ideas & 50 ideas \\
\hline $\begin{array}{c}\text { Idea } \\
\text { presentation }\end{array}$ & $\begin{array}{c}\text { Organize ideas into } \\
\text { categories }\end{array}$ & $\begin{array}{c}\text { Simple long } \\
\text { list }\end{array}$ \\
\hline $\begin{array}{c}\text { Procedural } \\
\text { guidance }\end{array}$ & $\begin{array}{c}\text { Sort ideas into high, } \\
\text { medium, low and then } \\
\text { finalize the high } \\
\text { category to reach their } \\
\text { top 10 shortlist }\end{array}$ & $\begin{array}{c}\text { Just simple } \\
\text { task } \\
\text { introduction }\end{array}$ \\
\hline
\end{tabular}

Upon arrival in the laboratory in the university, participants were given written tasks instructions and could freely ask questions for clarification before the first experiment activity commenced. Interactions between participants were not permitted to avoid potential awareness of the variations between experiment conditions. Subjects performed the experiment activities in ThinkTank, an online collaboration tool to support mass collaboration tasks.

We set a number of baselines for the experiment to ensure consistency between conditions. First, we controlled individuals' knowledge, individual capabilities, and experiences with the task. Second, we selected 50 ideas from the idea pool for low task complexity groups and all 100 ideas for high task complexity groups. We tested the differences of the quality scores between the 50 and 100 ideas groups (rated by separate raters, see section 4.3 for the details on this procedure). The difference is not significant $(t=1.629$, ns. $)$, which suggests that the average idea quality for low task complexity groups and the high task complexity groups is comparable.

\subsection{Rating procedure}

We recruited 5 postgraduate students to serve as raters of convergence quality and another 5 raters to assess idea generation quality. All raters were information and innovation majors that are experienced with technology supported innovation. The rating procedure lasted around two weeks. Raters were asked to rate independently and rate no more than 15 ideas per day to avoid rating inaccuracy caused by cognitive fatigue. Intraclass correlation coefficients (ICC) were used to measure interrater reliability [8]. The Cohen's Kappa for the 100 baseline ideas and newly generated ideas are $89.43 \%$ and $91.57 \%$ respectively. Inconsistencies were discussed until raters reached agreement.

We adopted the approach of Seeber et al. [11] to determine idea convergence quality. Convergence quality was measured through ratings of task relevance and the extent of idea elaboration. Six contextual dimensions were used to measure the extent of idea development, including purpose, participant, form, time, place and condition [40].

The rating criteria for generated ideas were based on the dimensions of creative ideas proposed by Dean et al. [41], including novelty, originality, relevance, elaboration, and feasibility.

\subsection{Measures}


Participants were asked to fill the questionnaires as soon as they finished the experiment activities. The questionnaire was comprised of three parts:

1. Participant demographics, including age, gender, past experience, and knowledge of the task topic.

2. A manipulation check as a secondary evaluation on the variations of manipulated variables (experiment conditions).

3. Individuals' perceptions of the three types of cognitive load and satisfaction with process and outcomes. We used a seven-point Likert-type scale for each item (strongly disagree to strongly agree). The items were adapted from validated scales from prior studies. Some items were reversed coded. All items are detailed in Appendix 1.

\section{Results}

We defined a unique task code that was assigned to each participant at the start of an experiment session. Each task code corresponded to one of eight different conditions. For example, task code 1.01 represents the first participant that was assigned to the first condition. Participants were asked to fill their task codes in questionnaires. Of the 172 questionnaires participants completed, we matched the results with the records in ThinkTank through the mapping of task codes. We removed incomplete questionnaires (with over 20\% missing items) and invalid ones (where the task code did not match with the records in ThinkTank). The final valid sample for analysis was 157 .

\subsection{Descriptive statistics}

The female to male ratio was $70.66 \%$ to $29.34 \%$, and the 18-20 group accounted for $80.24 \%$, followed by the 21-24 group, which accounted for $10.18 \%$. The idea selection and combination experiences vary evenly across all the participants. Subjects' knowledge level on technology enabled healthy life styles also vary evenly.
We calculated the mean, standards deviation, and factor loadings of each items using SPSS 22. The results are shown in table 2 below. The factor loadings were all above 0.7 , exceeding the acceptable level.

Table 2. Mean, Standard deviation and factor loadings

\begin{tabular}{|c|c|c|c|c|}
\hline & Items & $\begin{array}{c}\text { Factor } \\
\text { loadings }\end{array}$ & Mean & SD \\
\hline \multirow{2}{*}{$\begin{array}{c}\text { Intrinsic } \\
\text { cognitive } \\
\text { load }\end{array}$} & ICL1 & 0.765 & 4.11 & 1.448 \\
\cline { 2 - 5 } & ICL2 & 0.864 & 3.52 & 1.559 \\
\cline { 2 - 5 } & ICL3 & 0.882 & 3.31 & 1.422 \\
\hline \multirow{2}{*}{$\begin{array}{c}\text { Extraneous } \\
\text { cognitive } \\
\text { load }\end{array}$} & ECL1 & 0.864 & 3.48 & 1.530 \\
\cline { 2 - 5 } & ECL2 & 0.862 & 3.35 & 1.463 \\
\cline { 2 - 5 } & ECL3 & 0.869 & 3.40 & 1.395 \\
\hline $\begin{array}{c}\text { Germane } \\
\text { cognitive } \\
\text { load }\end{array}$ & GCL1 & 0.701 & 5.42 & 1.260 \\
\cline { 2 - 5 } & GCL2 & 0.773 & 5.01 & 1.249 \\
\cline { 2 - 5 } & GCL3 & 0.798 & 4.79 & 1.315 \\
\cline { 2 - 5 } & GCL4 & 0.824 & 4.82 & 1.301 \\
\cline { 2 - 5 } & GCL5 & 0.846 & 5.29 & 1.120 \\
\hline Satisfaction & SP1 & 0.849 & 4.35 & 1.449 \\
\cline { 2 - 5 } with & SP2 & 0.853 & 4.49 & 1.403 \\
\cline { 2 - 5 } & SP3 & 0.934 & 4.35 & 1.279 \\
\cline { 2 - 5 } & SP4 & 0.731 & 4.31 & 1.408 \\
\hline Satisfaction & SO1 & 0.895 & 4.67 & 1.387 \\
\cline { 2 - 5 } $\begin{array}{c}\text { with } \\
\text { outcome }\end{array}$ & SO2 & 0.939 & 4.49 & 1.407 \\
\cline { 2 - 5 } & SO3 & 0.932 & 4.46 & 1.398 \\
\cline { 2 - 5 } & SO4 & 0.897 & 4.65 & 1.445 \\
\hline
\end{tabular}

\subsection{Validity and reliability of measures}

We conducted composite reliability (CR) and internal consistency and discriminant validity and applied exploratory and confirmatory factor analysis using SPSS 22 and SmartPLS 3.0. The results are shown in table 3 . The composite reliability (CR) and the Cronbach's $\alpha$ for all constructs exceeded 0.7. The average variance extracted (AVE) for each construct was greater than 0.5 . The presence of indicators' outer loadings all exceed the cross loadings, which suggest that discriminant validity is not an issue. Therefore, reliability and validity are all acceptable.

Table 3. Estimates of reliability and validity

\begin{tabular}{|l|l|l|l|l|l|l|l|l|l|l|}
\hline & CR & $\alpha$ & AVE & 1 & 2 & 3 & 4 & 5 & 6 & 7 \\
\hline 1.Convergence quality & 1.000 & 1.000 & 1.000 & 1.000 & & & & & & \\
\hline $\begin{array}{l}\text { 2.Extraneous cognitive } \\
\text { load }\end{array}$ & 0.881 & 0.825 & 0.649 & -0.021 & 0.806 & & & & & \\
\hline 3.Germane cognitive load & 0.881 & 0.843 & 0.556 & 0.172 & -0.445 & 0.746 & & & & \\
\hline 4.Intrinsic cognitive load & 0.892 & 0.840 & 0.673 & -0.055 & 0.424 & -0.364 & 0.820 & & & \\
\hline
\end{tabular}




\begin{tabular}{|l|l|l|l|l|l|l|l|l|l|l|}
\hline 5.New idea quality & 1.000 & 1.000 & 1.000 & 0.057 & 0.037 & -0.113 & 0.037 & 1.000 & & \\
\hline $\begin{array}{l}\text { 6.Satisfaction with } \\
\text { outcome }\end{array}$ & 0.954 & 0.936 & 0.839 & -0.003 & -0.305 & 0.319 & -0.469 & -0.005 & 0.916 & \\
\hline 7.Satisfaction with process & 0.909 & 0.866 & 0.715 & 0.039 & -0.454 & 0.465 & -0.566 & -0.043 & 0.729 & 0.845 \\
\hline
\end{tabular}

\subsection{Manipulation check}

We conducted a manipulation check by asking the participants about the perceived difficulty of the activity, the perception on whether the idea presentation is clear, and the perceived usefulness of the guidance to execute the activities. The results show that the groups with high task complexity have significantly higher perceptions on task difficulty $(\mathrm{F}=3.796, \mathrm{p}<0.05)$. The groups with categorized idea presentation reported higher positive perceptions on the presentation of the ideas $(\mathrm{F}=3.966, \mathrm{p}<0.05)$. The groups with procedural guidance reported higher perceptions on the usefulness of the instructions $(\mathrm{F}=7.686, \mathrm{p}<0.01)$.

\subsection{Results of model testing}

5.4.1. The effects of the three interventions on the corresponding cognitive loads. We ran a MANCOVA test to check the effects of three treatment interventions on the three cognitive loads. We did not find significant results on interaction effects of three treatments on intrinsic cognitive load ( $\mathrm{F}=1.009$, ns.), extraneous cognitive load ( $\mathrm{F}=0.956$, ns.) and germane cognitive load ( $\mathrm{F}=0.932$, ns.) respectively.

Since the knowledge and experiences of the participants are diversified (the mean of knowledge is 3.53 , standard deviation is 1.54 ; the mean value of experiences is 2.99 , the standard deviation is 1.61 ), we included knowledge and experiences of individuals as the covariates. Results show that the effect of task complexity on intrinsic cognitive load is significant $(\mathrm{F}=3.253, \mathrm{p}<0.01)$. The effect of idea presentation on extraneous cognitive load is significant $(\mathrm{F}=1.997$, $\mathrm{p}<0.05$ ). The effect of procedural guidance on germane cognitive load is also significant $(\mathrm{F}=2.406, \mathrm{p}<0.05)$. Thus, the three experiment manipulations were validated.

Considering individuals heterogeneity of knowledge and past experiences, the results suggest that higher task complexity is associated with higher intrinsic cognitive load, idea organization is associated with lower extraneous cognitive load, and procedural guidance is associated with higher germane cognitive load.

5.4.2. The effects of the three types of cognitive load on satisfaction with process/outcome, convergence quality, and new idea quality. We conducted path coefficient analysis through SmartPLS 3.0. The model fit is acceptable, with $\chi^{2} / \mathrm{df}=2.76$. Detailed results of the path modeling testing are shown in table 4 . The $\mathrm{R}^{2}$ value for satisfaction with process, satisfaction with outcome, new idea quality and convergence quality are $0.421,0.248,0.043$, and 0.034 respectively.

We also checked the correlations between convergence quality and new idea generation quality. The Pearson correlation is $0.058, \mathrm{p}=0.472$. This suggests that convergence quality and new idea generation quality are not significantly correlated.

Table 4. Results of model testing

\begin{tabular}{|l|l|l|l|}
\hline Hypothesis & Estimates & T value & Results \\
\hline H1a & -0.015 & $0.142^{\text {ns }}$ & Rejected \\
\hline H1b & 0.074 & $0.735^{\text {ns }}$ & Rejected \\
\hline H1c & 0.202 & $2.086^{*}$ & Supported \\
\hline H2a & 0.094 & $0.924^{\text {ns }}$ & Rejected \\
\hline H2b & -0.003 & $0.033^{\text {ns }}$ & Rejected \\
\hline H2c & -0.175 & $2.046^{*}$ & Rejected \\
\hline H3a & -0.405 & $6.207^{* * *}$ & Supported \\
\hline H3b & -0.176 & $2.116^{*}$ & Supported \\
\hline H3c & 0.240 & $3.825^{* * *}$ & Supported \\
\hline H4a & -0.407 & $5.206^{* * *}$ & Supported \\
\hline H4b & -0.082 & $0.828^{\text {ns }}$ & Rejected \\
\hline H4c & 0.170 & $2.316^{*}$ & Supported \\
\hline
\end{tabular}

\section{Discussion}

Open innovative crowdsourcing is an emerging phenomenon that attracts the contributions from online crowds. The convergence of mass contributions and the idea generation process for the creation of creative ideas require high levels of cognitive loads. Our research is based on cognitive load theory to explore different interventions in a laboratory experiment. Specifically, we examined the effects of three interventions corresponding to three types of cognitive loads on satisfaction with process/outcome, convergence quality, and new idea generation quality.

We found that the influence of our interventions is significant when we control for individual differences in terms of knowledge and experiences. This may result from the sampling of the experiment in that the distribution of participants over conditions is heterogeneous in terms of their cognitive skills to process the information presented. 
Our results further show 1) a negative association of intrinsic cognitive load with satisfaction with process and satisfaction with outcome; 2) a negative association of extraneous cognitive load with satisfaction with process;. 3)a positive association of germane cognitive load on satisfaction with process, satisfaction with outcome and convergence quality. However, germane cognitive load appears to be negatively associated with new idea generation quality.

\subsection{Theoretical contributions}

This study contributes to the emerging literature on open innovative crowdsourcing. First, it contributes to our current understanding of how different intervention mechanisms may influence idea generation and convergence outcomes by incorporating cognitive load theory [10] to understand the cognitive processes of information processing in open innovation settings.

Second, the present study has implications for cognitive load theory. Compared with existing cognitive load studies that mostly focus on educational contexts [10] and incorporate cognitive load as a construct in the research model [35], this research highlights interventions of three types of cognitive load as influencing mechanisms on idea convergence and generation success.

Third, this study contributes to research on idea generation in open innovative communities, especially from the perspective of conceptual combination [6]. Our results suggest that, surprisingly, germane cognitive load leads to lower idea generation quality. This finding calls for follow-up research to uncover the relationships between germane cognitive load and the conceptual combination process in crowdsourcing communities.

Finally, this study goes beyond existing studies in idea crowdsourcing by studying the holistic process of idea convergence and generation [11]. Specifically, we studied idea convergence preceding a special form of idea generation (conceptual combination). Conceptual combination, as an idea generation technique that capture the richness of the original idea set, is studied through cognitive influencing mechanisms in this study.

\subsection{Practical contributions}

Our research also offers insights for practitioners. Convergence quality was found to be positively related to germane cognitive load. Extraneous cognitive load has a negative relationship with new idea generation quality, while germane cognitive load was positively related to new idea generation quality. We found that under differing conditions, there are correlations between perceived cognitive load and some dependent variables. Further, we found no correlations between perceived cognitive load and other dependent variables. The studied interventions offer suggestions for process designs for improved idea convergence quality and new idea generation quality, as well as higher levels of satisfaction.

Practitioners should be aware that, under the conditions in this study, germane cognitive load, as a form of cognitive load that is encouraged to be maximized, appears to be useful for idea convergence but not for new idea generation (conceptual combination). One explanation may be that the participants in this study were not willing to be confined too much during the final ideation activity. Future research should explore this possibility as well as identify other possible explanations.

\subsection{Limitations and future research}

This work still has some limitations. First, we recruited participants from a Chinese university with more females than males. Thus, the sample in our study suffers from an uneven distribution of gender. Another limitation concerning the external validity of the study stems from the use of student participants. In future research, we aim to conduct experiments in a wider range of participants with diversified backgrounds. Second, we measured cognitive load using subjective perceptions. This may not reflect actual cognitive load levels from a physiological point of view. Future research could use eye-tracking and fMRI to corroborate the perceptual measurements.

\section{Acknowledgement}

The authors would like to thank the National Natural Science Foundation of China (Grant No.71571045), and the Postgraduate Innovative Research Fund of University of International Business and Economics (Grant Number 76160601) for providing funding for part of this Research.

\section{References}

[1] M. Palacios, A. Martinez-Corral, A. Nisar, and M. Grijalvo, "Crowdsourcing and organizational forms: Emerging trends and research implications", Journal of Business Research, 2016, 69(5), pp.1834-1839.

[2] J. Prpić, P.P. Shukla, J.H. Kietzmann, and I.P. McCarthy, "How to work a crowd: Developing crowd capital through crowdsourcing", Business Horizons, 2015, 58(1), pp.77-85.

[3] I.Blohm, C. Riedl,J. Füller,and J.M. Leimeister, "Rate or trade? Identifying winning ideas in open idea 
sourcing”, Information Systems Research, 2016, 27(1), pp. $27-48$

[4] C. Nguyen, N. Tahmasbi, T. de Vreede, G.J. de Vreede, O. Oh, R. Reiter-Palmon, "Participant Engagement in Community Crowdsourcing", in Proceedings of the 23rd European Conference on Information Systems, Munich, Germany, 2015, pp.1-11.

[5] B. Lee, S. Ba,X. Li, and J. Stallaert, "Salience Bias in Crowdsourcing Contests", Information Systems Research, 2018, Forthcoming.

[6] I.A. Zolkepli, H. Hasno, S. Mukhiar, and S. Nadiah, "Online Social Network Citizen Engagement on Instagram Crowdsourcing: A Conceptual Framework", Electronic Journal of Knowledge Management, 2015, 13(4), pp.283-292. [7] H. Zheng, D. Li, and W. Hou, "Task design, motivation, and participation in crowdsourcing contests", International Journal of Electronic Commerce, 2011, 15(4), pp.57-88.

[8] K.Girotra, C. Terwiesch, and K.T. Ulrich, "Idea generation and the quality of the best idea", Management science, 2010, 56(4),pp.591-605.

[9] E.L. Santanen, R. O. Briggs, and G.J. de Vreede, "Causal relationships in creative problem solving: Comparing facilitation interventions for ideation", Journal of Management Information Systems, 2014, 20(4), pp.167-198. [10] F. Paas, A. Renkl, and J. Sweller, "Cognitive load theory: Instructional implications of the interaction between information structures and cognitive architecture", Instructional Science, 2004, 32(2), pp.1-8.

[11] I. Seeber, G.J. de Vreede, R. Maier, and B. Weber, "Beyond Brainstorming: Exploring Convergence in Teams", Journal of Management Information Systems, 2017, 34(4), pp.939-969.

[12] L. Rhee, and P.M. Leonardi, "Which pathway to good ideas? An attention - based view of innovation in social networks", Strategic Management Journal, 2018, 39(4), pp.1188-1215.

[13] Tapscott B., and Williams A.D. "Wikinomics: How mass collaboration changes everything", New York: Penguin Group, 2008.

[14] J.M. Leimeister, M. Huber, U. Bretschneider, and H. Krcmar, "Leveraging crowdsourcing -activation-supporting components for IT-based idea competitions", Journal of Management Information Systems, 2009, 26(1), pp.197-224.

[15] Y. Zhao, and Q. Zhu, "Evaluation on crowdsourcing research: Current status and future direction," Information Systems Frontiers, 2014, 16(3), pp.417-434.

[16] R.O. Briggs, G.J. De Vreede, and J. F. Nunamaker Jr, "Collaboration engineering with ThinkLets to pursue sustained success with group support systems", Journal of management information systems, 2003, 19(4), pp.31-64.

[17] S.M. Staggs, J.A. Bonito, and J.N. Ervin, "Measuring and evaluating convergence processes across a series of group discussions", Group Decision and Negotiation, 2018, 1, pp.1-19.

[18] E.F. Rietzschel, B.A. Nijstad, and W. Stroebe, "The selection of creative ideas after individual idea generation: Choosing between creativity and impact", British journal of psychology, 2010, 101(1), pp.47-68.

[19] F.J. Costello, and M.T. Keane, "Efficient creativity: Constraint-guided conceptual combination", Cognitive Science, 2000, 24(2), pp.299-349.
[20] E.J. Wisniewski, "Construal and similarity in conceptual combination", Journal of Memory and Language, 1996, 35(3), pp.434-453.

[21] L.L. Yu, and J.V. Nickerson, "Generating creative ideas through crowds: An experimental study of combination", in Proceedings of the thirty-second international conference on information systems, Shanghai, China, 2011, pp.1-16.

[22] T. Montag-Smit, and C.P. Maertz Jr, "Searching outside the box in creative problem solving: The role of creative thinking skills and domain knowledge", Journal of Business Research, 2017, 81, pp.1-10.

[23] H.L. Swanson, X. Zheng, and O. Jerman, "Working memory, short-term memory, and reading disabilities: A selective meta-analysis of the literature", Journal of Learning Disabilities, 2009, 42(3), pp.260-287.

[24] M.P. Cook, "Visual representations in science education: The influence of prior knowledge and cognitive load theory on instructional design principles", Science education, 2006, 90(6), pp.1073-1091.

[25] Q. Wang, S. Yang, M. Liu, Z. Cao, and Q. Ma, "An eyetracking study of website complexity from cognitive load perspective", Decision support systems,2014, 62, pp.1-10.

[26] C.C. Chang, C. Liang, C., P.N. Chou, and G.Y. Lin, "Is game-based learning better in flow experience and various types of cognitive load than non-game-based learning? Perspective from multimedia and media richness", Computers in Human Behavior, 2017, 71, pp.218227.

[27] B. Zhu, and S.A. Watts, "Visualization of network concepts: The impact of working memory capacity differences", Information Systems Research, 2010, 21(2), pp.327-344.

[28] O.W. Hong, J.Y. Thong, and K.Y. Tam, "The effects of information format and shopping task on consumers' online shopping behavior: A cognitive fit perspective", Journal of Management Information Systems,2004, 21(3), pp.149-184. [29] M.U. Kayande, A. De Bruyn, G. L. Lilien, A. Rangaswamy, and G.H. Van Bruggen, "How incorporating feedback mechanisms in a DSS affects DSS evaluations", Information Systems Research, 2009, 20(4), pp.527-546.

[30] R.M. den Hengst, and M. Adkins, "Which collaboration patterns are most challen- ging: A global survey of facilitators", In Proceedings of the 40th Annual Hawaii International Conference on System Sciences. Los Alamitos, CE: IEEE Computer Society Press, 2007, pp. 1-10.

[31] S. Fu, G.J. de Vreede, X. Cheng, I. Seeber, R. Maier, B. Weber, "Convergence of Crowdsourcing Ideas: A Cognitive Load perspective", in Proceedings of the 34rd International Conference of Information System (ICIS), Seoul, Korea, 2017, pp.1-11.

[32] R.E. Potter, and P. Balthazard, "The role of individual memory and attention processes during electronic brainstorming”, MIS Quarterly, 2004, 28(4), pp.621-643.

[33] Paulus P., and Nakui T., "Facilitation of Group Brainstorming", in The IAF Handbook of Group Facilitation, S. Schuman (ed.). San Francisco: Jossey-Bass, 2015, pp.103114.

[34] J. Fjermestad, and S.R. Hiltz, “An Assessment of Group Support Systems Experimental Research: Methodology and 
Results", Journal of Management Information Systems, 1998,15(3), pp.7-149.

[35] J.M. Hender, D.L. Dean, T.L. Rodgers, and J. F. Nunamaker Jr, "An examination of the impact of stimuli type and GSS structure on creativity: Brainstorming versus nonbrainstorming techniques in a GSS environment", Journal of Management Information Systems, 2002, 18(4), pp.59-85.

[36] A.R. Dennis, R.K. Minas, and A.P. Bhagwatwar, "Sparking Creativity: Improving Electronic Brainstorming with Individual Cognitive Priming", Journal of Management Information Systems, 2013, 29(4), pp.195-216.

[37] D. Laureiro - Martínez, and S. Brusoni, "Cognitive flexibility and adaptive decision - making: Evidence from a laboratory study of expert decision makers", Strategic Management Journal, 2018, 39(4), pp.1031-1058.

[38] R.O. Briggs, G.L. Kolfschoten, G.J. de Vreede, S. Lukosch, and C.C. Albrecht, "Facilitator-in-a-box: process support applications to help practitioners realize the potential of collaboration technology", Journal of Management Information Systems, 2013, 29(4), pp.159-194.

[39] R. Ladhari, and M. Michaud, "eWOM effects on hotel booking intentions, attitudes, trust, and website perceptions", International Journal of Hospitality Management, 2015, 46, pp.36-45.

[40] J. Yates, and W. Orlikowski, "Genre systems: Structuring interaction through communicative norms", The Journal of Business Communication, 2002, 39(1), pp.13-35.

[41] D.L. Dean, J.M. Hender, T.L. Rodgers, and E. Santanen, "Identifying good ideas: constructs and scales for idea evaluation", Journal of the Association for Information Systems, 2006, 10(7), pp.646-699.

[42] J.Cheon, and M. Grant, "Examining the relationships of different cognitive load types related to user interface in webbased instruction", Journal of Interactive Learning Research, 2012, 23(1), pp.29-55.

[43] B.A. Reinig, "Toward an Understanding of Satisfaction with the Process and Outcomes of Teamwork", Journal of Management Information Systems, 2003, 19(4), pp.65-83.

\section{Appendix 1:}

This is a post-experiment survey that aims to evaluate participants' perceptions of the cognitive loads, satisfaction with process, and satisfaction with outcome. Please choose value scale from 1 to 7 , $1=$ Strongly disagree, $2=$ Disagree, $3=$ Slightly disagree, 4=Neutral, 5=Slightly agree, $6=$ Agree, 7=Strongly agree.

\begin{tabular}{|l|l|l|}
\hline Constructs & Measurements & Items \\
\hline $\begin{array}{l}\text { Intrinsic } \\
\text { cognitive load } \\
\text { (Adapted from }\end{array}$ & The task is complex. & ICL1 \\
\cline { 2 - 3 }$[26])$ & $\begin{array}{l}\text { The task is not easy to } \\
\text { comprehend. }\end{array}$ & ICL2 \\
\cline { 2 - 3 } & $\begin{array}{l}\text { The task is beyond my } \\
\text { competence. }\end{array}$ & ICL3 \\
\hline $\begin{array}{l}\text { Extraneous } \\
\text { cognitive load } \\
\text { (Adapted from }\end{array}$ & $\begin{array}{l}\text { I do not like the } \\
\text { presentation } \\
\text { organization of the ideas. }\end{array}$ & ECL1 \\
\hline
\end{tabular}

\begin{tabular}{|c|c|c|}
\hline \multirow[t]{2}{*}[26]{)} & $\begin{array}{l}\text { I am not comfortable with } \\
\text { the presentation or } \\
\text { organization of the ideas. }\end{array}$ & ECL2 \\
\hline & $\begin{array}{l}\text { The presentation or } \\
\text { organization of the ideas is } \\
\text { not helpful for me to } \\
\text { process. }\end{array}$ & ECL3 \\
\hline \multirow{5}{*}{$\begin{array}{l}\text { Germane } \\
\text { cognitive load } \\
\text { (Adapted from } \\
{[42] \text { ) }}\end{array}$} & $\begin{array}{l}\text { The guidance contributed } \\
\text { to my processing of the } \\
\text { ideas. }\end{array}$ & GCL1 \\
\hline & $\begin{array}{l}\text { The guidance really } \\
\text { enhanced my deliberation } \\
\text { of the ideas. }\end{array}$ & GCL2 \\
\hline & $\begin{array}{l}\text { As we progressed } \\
\text { throughout the activities, } \\
\text { the guidance helped me to } \\
\text { concentrate on the } \\
\text { processing of the ideas. }\end{array}$ & GCL3 \\
\hline & $\begin{array}{l}\text { While proceeding } \\
\text { throughout the activities, } \\
\text { the guidance helped me to } \\
\text { better complete my task. }\end{array}$ & GCL4 \\
\hline & $\begin{array}{l}\text { The guidance makes it } \\
\text { easy for me to do similar } \\
\text { tasks again. }\end{array}$ & GCL5 \\
\hline \multirow{4}{*}{$\begin{array}{l}\text { Satisfaction } \\
\text { with process } \\
\text { (Adapted from } \\
{[38] \text { ) }}\end{array}$} & $\begin{array}{l}\text { I feel good about today's } \\
\text { idea processing. }\end{array}$ & SP1 \\
\hline & $\begin{array}{l}\text { I liked the way the } \\
\text { activities } \\
\text { today. }\end{array}$ & SP2 \\
\hline & $\begin{array}{l}\text { I feel satisfied with the } \\
\text { procedures used in } \\
\text { processing the ideas. }\end{array}$ & SP3 \\
\hline & $\begin{array}{l}\text { I feel satisfied about the } \\
\text { way I carried out the idea } \\
\text { processing. }\end{array}$ & SP4 \\
\hline \multirow{4}{*}{$\begin{array}{l}\text { Satisfaction } \\
\text { with outcome } \\
\text { (Adapted from } \\
{[38] \text { ) }}\end{array}$} & I liked the outcome. & SO1 \\
\hline & $\begin{array}{l}\text { When the idea processing } \\
\text { was over, I felt satisfied } \\
\text { with the results. }\end{array}$ & $\mathrm{SO} 2$ \\
\hline & $\begin{array}{l}\text { My accomplishments } \\
\text { today give me a feeling of } \\
\text { satisfaction. }\end{array}$ & SO3 \\
\hline & $\begin{array}{l}\text { I am happy with the } \\
\text { results of today's idea } \\
\text { processing. }\end{array}$ & $\mathrm{SO} 4$ \\
\hline
\end{tabular}

